\title{
Review
}

\section{Dietary Recommendation in Diabetes Care: Carbohydrate Counting and Caloric Content of Nigerian Foods}

\author{
Taoreed Azeez, MBChB, MWACP, MSc ${ }^{1 *}$; Patience Chimah, BSc, MSc'2;Abdul F. Hassan, MBBS, MWACP ${ }^{3}$ \\ Yusuf Moradeyo, MBBS, MWACP ${ }^{4}$; Ubong Umoren, MBBS, MWACP5; Emmanuel Eguzozie, MBBS, MWACP' \\ 'Endocrinology, Metabolism and Diabetes Unit, Department of Medicine, University College Hospital, Ibadan, Nigeria \\ ${ }^{2}$ Department of Nutrition and Dietetics, Lagos University Teaching Hospital, Lagos, Nigeria \\ ${ }^{3}$ Department of Internal Medicine, University of Maiduguri Teaching Hospital, Maiduguri, Nigeria \\ ${ }^{4}$ Department of Medicine, Benue State University Teaching Hospital, Makurdi, Nigeria \\ ${ }^{5}$ Endocrinology, Metabolism and Diabetes Unit, Department of Medicine, University of Uyo Teaching Hospital, Uyo, Nigeria
}

\section{"Corresponding authors}

Taoreed Azeez, MBChB, MWACP, MSc

Endocrinology, Metabolism and Diabetes Unit, Department of Medicine, University College Hospital, Ibadan, Nigeria; E-mail: adegokegalaxy@yahoo.com

\section{Article information}

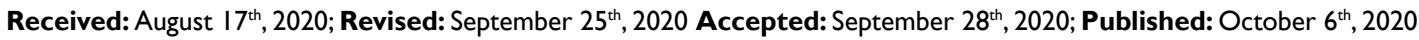

\section{Cite this article}

Azeez T, Chimah P, Hassan AF, Moradeyo Y, Umoren U, Eguzozie E. Dietary recommendation in diabetes care: Carbohydrate counting and caloric content of Nigerian foods. Adv Food Technol Nutr Sci Open J. 2020; 6(2): 53-59. doi: 10.17140/AFTNSOJ-6-169

\section{ABSTRACT}

The prevalence of diabetes mellitus is rising globally and even more in low and middle-income countries such as Nigeria. Optimal management of the disease is important to improve survival and prevent or delay its complications. Lifestyle management is a standard universal approach in optimizing the care given to diabetic patients. Dietary management is the central link in lifestyle modifications of individuals living with diabetes. Medical nutrition therapy (MNT) is a systematic therapeutic approach of assessing the nutritional needs of an individual, determining nutritional goals, counselling the clients on how to achieve the goals, prescribing and monitoring meal plans to achieve the goals. It is evidence-based, effective and highly recommended. All carers of the diabetes patient, including the health workers and the family members of the patients, need to have basic understanding of medical nutrition therapy but the efforts should be coordinated by licensed dietitians. There are evidences that adherence to prescribed calories is effective in the control of cardiovascular risk factors such as blood glucose, weight, lipid profile and blood pressure. However, prescription of calories should be based on thoughtful consideration of the nutritional needs, weight goal, personal preferences and tastes and cultural practices of individuals living with diabetes mellitus. Food pyramids give a graphical illustration on the recommended classes and servings of food. Six to eleven servings per day of carbohydrates, 3-5 servings per day of vegetables, 2-4 servings per day of fruit, 2-3 servings per day of dairy products and 2-3 servings per day of fish are the recommended proportions of the different classes of foods for an adult on an average of 2000 calories. Carbohydrate counting, taken with appropriate insulin dosing and physical activity, has been demonstrated to be effective in optimizing the glycaemic control of patients on multiple daily insulin injections. There are challenges in doing this in Nigeria due to lack of food labels. The caloric contents of common Nigerian foods are highlighted so as to help in achieving dietary goals.
\end{abstract}

Keywords

Diabetes care; Dietary approach; Carbohydrate counting; Caloric content of Nigerian foods.

\section{BACKGROUND}

L ifestyle management is the pedestal of optimal care in individuals with diabetes and dietary approach is the central theme of lifestyle modification. Healthy eating is the cornerstone of glycaemic control in diabetes mellitus. ${ }^{1}$ Glycaemic control refers to the methodical approach to achieving the glucose targets (Fasting blood glucose, postprandial glucose and glycated haemoglobin) of patients with diabetes mellitus depending on the adopted guide- lines. However, recommendation about dietary management may be difficult in Nigeria, where the number of registered dietitians under employment is limited. Also, there is lack of knowledge of the caloric contents of Nigerian foods. The notion of 'diabetic diet' which involves a lot of dietary restriction is being replaced with 'healthy diet' which is having a dietary plan adequate in nutrients and moderate caloric and fat contents. So, the 'healthy diet' is the recommended diet for everyone. This makes the individuals living with diabetes mellitus feel socially acceptable while also en- 
couraging them to comply with their recommendation.

Patients with diabetes are expected to see the dietitians, at least, at diagnosis. However, in low resource settings, availability of professional dietitians under employment is limited so, it is important for all carers of patients with diabetes, including their family members, to understand the dietary approach to their care. Nigeria is a multicultural society with various kinds of foods and food preparations. ${ }^{2}$ Dietary management in patients with diabetes and prediabetes is aimed not only at optimizing glycaemic control but also at control of other cardiovascular risk parameters such as weight, lipids and blood pressure. ${ }^{3}$ Consumption of excess calories, even without causing hyperglycaemia, is an independent cardiovascular risk. ${ }^{3}$ Dietary prescription involves a collaboration among the patient and his family, the dietitian and the physician based on health targets (such as weight and blood glucose readings), cultural values, lifestyle, dietary preference and taste. ${ }^{4}$

Healthy sources of carbohydrates available in Nigeria include whole grains (such as rice, maize and millet) and legumes (such as beans and groundnut). Low fat dairy foods such as milk or cheese are also recommended. As healthy as they are, studies have demonstrated that the knowledge of the health benefits as well as the consumption of fruits and vegetables is very low among Nigerians despite the extensive availability of varieties of fruits and vegetables. ${ }^{5}$ Consumption of sugary beverages with extra calories is often discouraged but a study documented a high-level of consumption of sweetened beverages among Nigerians. ${ }^{6}$ Saturated fats are discouraged but food sources such as organ meat (kidney, intestine and liver) rich in saturated fats are commonly consumed in Nigeria. ${ }^{7}$ High salt intake (more than 5 grams of salt per day) which is unhealthy is prevalent in Nigeria and many other sub-Saharan countries, as reported by a meta-analysis. ${ }^{8}$ The plate method of meal planning recommended by the American Diabetes Association (ADA) involves filling half of the serving plate with vegetables, a quarter of the plate with carbohydrates and the remaining quarter with proteins. ${ }^{9}$ A serving of dairy and a cup of water can accompany the plate. This is not practiced among Nigerians with or without diabetes mellitus. ${ }^{7}$

Carbohydrate counting has beneficial effects on glycaemic control. ${ }^{10}$ It helps in determining the appropriate insulin doses to prevent fluctuating glycaemic patterns. It adds flexibility to the management and engenders compliance. In Nigeria, more efforts are tailored towards controlling glucose excursions by appropriately adjusting insulin doses rather than teaching and practicing carbohydrate counting. ${ }^{1}$ This is partly due to the fact that there are insufficient data on the carbohydrate and caloric contents of Nigerian foods and the methods of food preparation for consumption vary remarkably from one region to the other. ${ }^{11}$

It is a common dietary advice to tell patients to lower their caloric intake. In the developed world, appropriate food packaging and compulsory food labelling make it relatively easy for patients to achieve their calorie targets. ${ }^{12}$ In Nigeria, foods are often prepared in households or at restaurants without any form of food labelling. ${ }^{13}$ Even among the elites who sometimes consume pack- aged meals, a study reported that they rarely check the labels and the few who check find them confusing. ${ }^{13}$ Variation in species and variants of the crops, food processing and food preparation also tend to make estimation of food caloric content inaccurate, hence why it is rarely focused on. ${ }^{12}$

\section{MEDICAL NUTRITIONTHERAPY |}

Medical nutrition therapy (MNT), also known as therapeutic nutrition is an evidence-based and systematic process of assessing the nutritional status and requirements of an individual, setting nutritional goals, counselling on how to achieve the goals, prescribing and monitoring meal plans to achieve the goals. ${ }^{14}$ The terminology 'medical nutrition therapy' was first used by the ADA in 1994 but the concept of recommending diets for patients with diabetes dates back to antiquity. ${ }^{14}$ Several researchers have documented the clinical benefits of MNT in the management of diabetes. ${ }^{14}$ Evidences from observational studies, cohort studies, randomized clinical trial and meta-analyses are in support of this assertion. Apart from the clinical benefits, economic studies have also found MNT to be cost-effective. ${ }^{15}$

While it is essential that every member of the diabetes care team knows about nutrition and is able to offer valuable nutritional advice, it is recommended that the dietitian should spearhead medical nutrition therapy. ${ }^{16}$ In fact, a meta-analysis documented that diabetic patients who received MNT from a registered dietitian had more reduction in glycated haemoglobin (HbA1c) compared with those who received dietary advice from nurses or physicians. ${ }^{17}$ In Nigeria, there are insufficient numbers of dietitians to provide MNT for all the diabetic patients as most of the registered ones cluster in urban centres, mostly at the secondary and tertiary levels of care.

Medical nutrition therapy emphasizes individualized care because fixed ratios of carbohydrates, proteins and fats cannot be applied to everyone with diabetes due to differences in their nutritional requirements. ${ }^{18}$ Mediterranean diet has been found to be the most effective diet type in terms of lowering of HbA1c. ${ }^{19}$ Mediterranean diet refers to the meal plans commonly consumed among countries bordering the Mediterranean Sea. There is no universal definition of Mediterranean diet, but it isessentially based on whole grains, fruits and vegetables, dairy products, use of healthy fats such as olive oil and minimization of red meat consumption. ${ }^{20}$ The pattern of eating among patients with diabetes in Nigeria is different from the Mediterranean diet as it is based on calorie-dense high carbohydrate diet. ${ }^{21}$ Also, in a developing nation like Nigeria, where there is paucity of dietitians under employment, fixed ratios of food classes is still being practiced. About $45-65 \%$ of the total daily calorie is allotted to carbohydrates, fats constitute about $25-35 \%$ and proteins constitute about $15-20 \%{ }^{1}$ It is also a common misconception among the diabetic population that consuming carbohydrates is tantamount to hyperglycaemia so, they tend to avoid carbohydrates or minimize its consumption. ${ }^{1}$

Prior to the landmark discovery of insulin and its com- 
after taking the food compared with a rise in glucose after ingesting a reference food (usually glucose or white bread). ${ }^{24}$ The glycemic index of a food multiplied by the amount of carbohydrate in the food gives the glycaemic load. ${ }^{24}$ Whole grains and legumes are good sources of carbohydrates because they have low glycaemicindices.

Considering prescription for fats, saturated fats should be limited to $<7 \%$, trans-fat is better avoided altogether while cholesterol should be limited to $<200 \mathrm{mg}$ per day. ${ }^{24}$ Monounsaturated fat is highly recommended. High protein diets are not recommended. Good quality proteins provide the 9 essential amino acids. Examples of quality protein that are available in Nigeria are fish, eggs, milk and poultry. Mineral or vitamin supplementation to the diets of people living with diabetes is not recommended. ${ }^{24}$ However, special groups such as elderly, pregnant or lactating women and individuals on very low calorie diet may benefit from supplementation. ${ }^{24}$

\section{FOOD PYRAMID}

Adequate diet is the diet that provides needed nutrients in a proportion that meets the physiological needs of an individual. Food pyramid is the scheme used to depict food classes and the appropriate proportion of each class. ${ }^{26}$ The pyramid is divided into layers and each layer corresponds to the relative amount and class of food. It is triangular and graphically represents food proportions designed in a way to support healthy eating. The base is represented by carbohydrates, and progressing upwards, this is followed by vegetables, followed by proteins and lastly fats and sweets. ${ }^{26}$ The progression from the base to the tip represents the relative quantity of each class to be consumed with the base representing the largest quantity and the tip representing the smallest quantity.

Generally, it is recommended to have 6-11 servings per

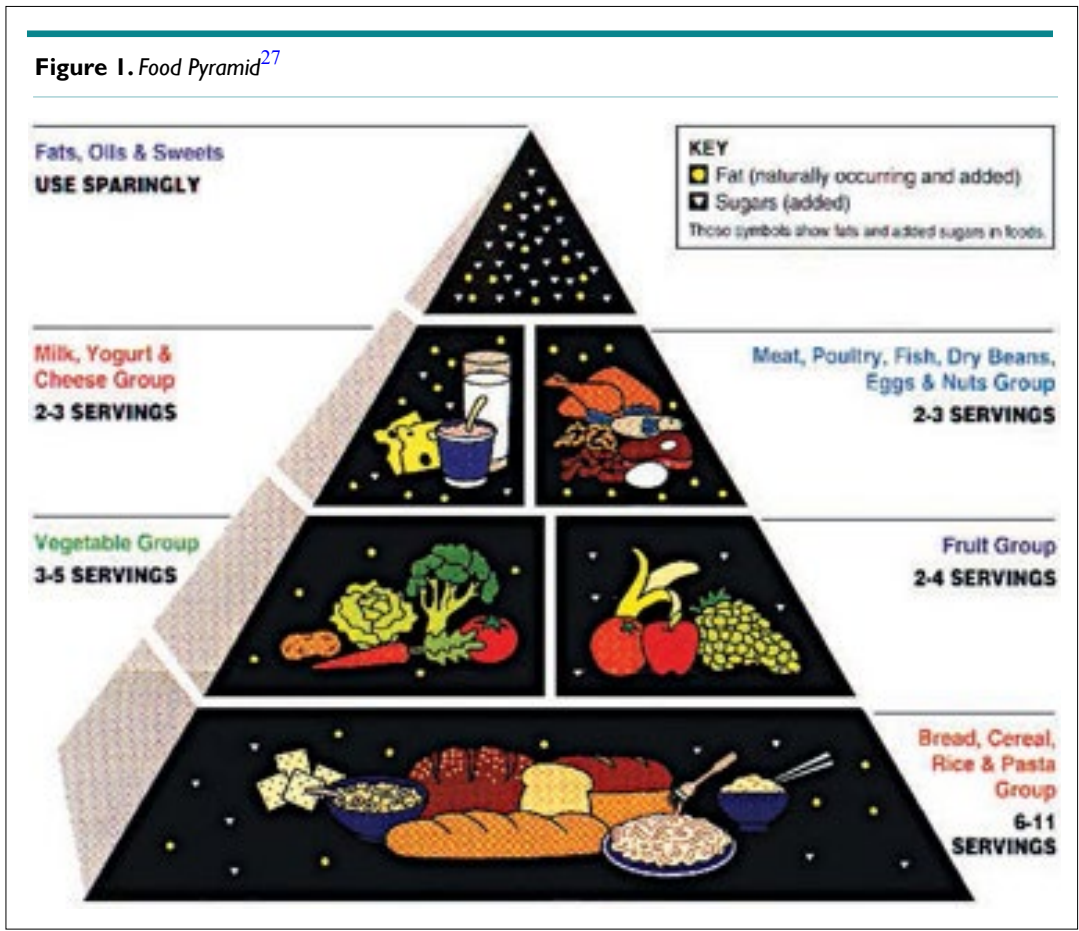


diet choices and timing of meals. It enables the patients with diabetes to take charge of their health and also to estimate amount of insulin required per certain amount of carbohydrates. ${ }^{28}$ Carbohydrate counting also assists the patient to observe how the blood glucose responds to different types of carbohydrate and how to respond to it appropriately by adjusting the insulin dose. It is however cumbersome for some people. Moreover, in low resource settings, such as Nigeria, where food labels are the exceptions and there are wide variations in food preparations, it is very difficult to practice food counting without the aid of a registered dietitian. ${ }^{13}$

This is a technique used by patients with diabetes to estimate the amount of carbohydrate in their meals. The carbohydrate quantity is determined in grams and a serving of carbohydrate is about 15 grams. ${ }^{28}$ The health care giver and the patient agree on how much carbohydrate to aim at so as to reach the nutritional goal. Appropriate combination of carbohydrate counting, physical activity and insulin dosing is important for optimal glycaemic control. Carbohydrate counting entails keeping track of the carbohydrate in the diets. It helps to stay healthy and prevent or delay the onset of complications of diabetes. The amount of carbohydrates is often inscribed on the food label.

Carbohydrate counting is illustrated as follows. Assuming the daily calorie recommendation for a man is $1800 \mathrm{Kcal}$ per day, it is recommended that carbohydrate should constitute about $50 \%$ of this total calorie level, thereby making total calories from carbohydrate, in this instance, $900 \mathrm{Kcal} .{ }^{1}$ Four kilocalories (Kcal) is derived from $1 \mathrm{~g}$ of carbohydrate, therefore $900 \mathrm{Kcal}$ will be derived from $225 \mathrm{~g}$ of carbohydrate. This can be divided into 3 meals and 1 to 2 snacks.

In Nigeria, carbohydrate counting is not usually advised during a dietary counseling session. Instead the recommendation used is to restrict one or more forms of carbohydrate. ${ }^{1}$ Most foods consumed are prepared at home or bought unpackaged or without a food label. However, it is now known that the amount of carbohydrate eaten is more important than the type because any carbohydrate consumed in sufficient quantity is capable of raising the blood glucose dramatically. ${ }^{1}$

Carbohydrate counting adds flexibility to the meal plans,

\section{CALORIE CONTENTS OF COMMON NIGERIAN FOODS AND DRINKS}

Foods are often culturally determined and Nigeria is a multicultural nation but there are certain foods that are commonly consumed in most households in Nigeria. There is a need to pay attention to calories so as to meet the dietary goals. Normally, a physically active man requires about 2000 calories per day and an average physically active woman requires 1800 calories per day. ${ }^{24}$ The main challenge of estimating calories in Nigeria foods is the varied methods of food preparations. Another challenge is the standard of measurement, which tends to vary also. Nutrition education is scarcely available to the populace, especially the rural area dwellers. ${ }^{29}$ The tables below show the estimated calories in various Nigerian foods and drink (Tables 1, 2, 3 and 4) . $^{30-33}$

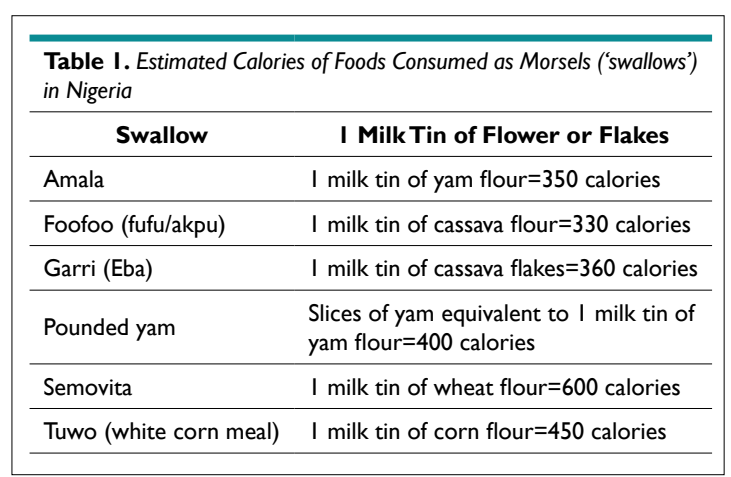

\begin{tabular}{|lcc|}
\hline Table 2. Estimated Calories in Beverages ('Drinks') in Nigeria \\
\hline Alcoholic Beverage & $\begin{array}{c}\text { Estimated Calorie Content } \\
\text { per } \mathbf{1 0 0} \text { ml of Beverage }\end{array}$ & $\begin{array}{c}\text { Caloric Contents in the } \\
\text { Bottles Commonly Sold }\end{array}$ \\
\hline Gulder & 55 calories & I bottle $(600 \mathrm{ml})=330$ calories \\
\hline Guinness & 45 calories & I bottle $(440 \mathrm{ml})=200$ calories \\
\hline Heineken & 35 calories & I bottle $(440 \mathrm{ml})=155$ calories \\
\hline Red wine $(13 \%$ alcohol) & 70 calories & I bottle $(750 \mathrm{ml})=525$ calories \\
\hline Champagne & 75 calories & I bottle $(750 \mathrm{ml})=560$ calories \\
\hline Non-Alcoholic Beverage & & I bottle $(600 \mathrm{ml})=250$ calories \\
\hline Coca-cola coke & 42 calories & I bottle $(600 \mathrm{ml})=220$ calories \\
\hline Fanta & 36 calories & I bottle $(600 \mathrm{ml})=240$ calories \\
\hline Pepsi & 40 calories & I bottle $(600 \mathrm{ml})=250$ calories \\
\hline 7 up & 42 calories & I bottle $(1000 \mathrm{ml})=660$ calories \\
\hline Hollandia yoghurt & 66 calories & I bottle $(330 \mathrm{ml})=190$ calories \\
\hline Maltina & 56 calories & I bottle $(1000 \mathrm{ml})=520$ calories \\
\hline Chi exotic & 52 calories & \\
\hline & & \\
\hline
\end{tabular}




\begin{tabular}{|c|c|c|}
\hline Food & $\begin{array}{c}\text { Estimated Calorie Content } \\
\text { per } 100 \mathrm{~g} \text { of Food }\end{array}$ & $\begin{array}{l}\text { Caloric Contents in } \\
\text { Specific Measures }\end{array}$ \\
\hline Rice & 150 calories & I tablespoon $=15$ calories \\
\hline Beans & I 40 calories & I tablespoon $=15$ calories \\
\hline Yam & 120 calories & I tuber=highly variable \\
\hline Bread & 300 calories & | slice $=\mid 20$ calories \\
\hline Egg & I50 calories & I egg $=70$ calories \\
\hline Granulated sugar & - & I tablespoon $=30$ calories \\
\hline Sugar cube & - & I cube $=10$ calories \\
\hline Honey & - & I tablespoon $=60$ calories \\
\hline Powdered milk & - & I tablespoon $=40$ calories \\
\hline Snail & 100 calories & - \\
\hline Palm oil/coconut oil & - & I tablespoon $=40$ calories \\
\hline Akara (beans cake) & - & I roll=70 calories \\
\hline Pap (akamu) & - & I tablespoon $=90$ calories \\
\hline Roasted corn & & $\begin{array}{l}\text { I medium size }=100 \\
\text { calories }\end{array}$ \\
\hline Goat meat & 100 calories & - \\
\hline Margarine/butter & - & I tablespoon $=100$ calories \\
\hline Egusi soup & & I serving $=500$ calories \\
\hline Ewedu soup & & I serving $=100$ calories \\
\hline Okra soup & & I serving $=\mid 50$ calories \\
\hline Bitter leaf soup & & I serving $=\mid 50$ calories \\
\hline Oha soup & & I serving $=\mid 80$ calories \\
\hline Stew & & I serving $=200$ calories \\
\hline
\end{tabular}

\begin{tabular}{|c|c|c|}
\hline Fruits & $\begin{array}{c}\text { Estimated Calorie Content } \\
\text { per } 100 \mathrm{~g} \text { of Fruit }\end{array}$ & $\begin{array}{l}\text { Approximate Calories } \\
\text { perAverage-sized Fruit }\end{array}$ \\
\hline Apple & 55 calories & 95 calories \\
\hline Banana & 85 calories & 105 calories \\
\hline Orange & 50 calories & 65 calories \\
\hline Pineapple & 50 calories & 450 calories \\
\hline Watermelon & 30 calories & 450 calories \\
\hline Mango & 60 calories & 200 calories \\
\hline Garden egg & 25 calories & 140calories \\
\hline Pawpaw & 80 calories & 180 calories \\
\hline
\end{tabular}

\section{CONCLUSION}

Diabetes mellitus is a common chronic disease globally and specifically in Nigeria. A central approach in its management is lifestyle modification. Dietary management is an integral part of the lifestyle modifications. Medical nutrition therapy involves assessing nutritional needs, setting nutritional goals and embarking upon dietary actions to achieve these goals. It also includes monitoring of the patients to ensure the dietary goals are achieved but not at the detriment of the health of the individuals. Dietitians are the primary professionals recommended to lead this effort but the registered dietitians in Nigeria are scanty and mostly distributed in the urban areas.
Food pyramids is a graphical representation of the balanced nutritious diets. Prescription of calories involves taking cognizance of factors such as food availability, weight targets, individual preferences and cultural beliefs and practices. The estimated caloric contents of the common Nigerian foods are highlighted in the tables. However, the exact caloric content is affected by species of crops, food processing and preparations and cultural practices.

\section{CONFLICTS OF INTEREST}

The authors declare that they have no conflicts of interest.

\section{REFERENCES}

1. Ugodadi NS, Onyenibe NS, Abdullahi MK. Dietary management of diabetes mellitus with focus on Nigeria. Int J Diabetes Res. 2019; 2(1): 2493. doi: 10.17554/j.issn.2414-2409.2019.02.14

2. Sanni SA, Oguntona CRB, Sanni LO. Chemical and nutritional composition of some common foods in Abeokuta, Nigeria. Braz Arch Biol Technol. 1999; 42(3): 1516-8913. doi: 10.1590/S151689131999000300010

3. Casas R, Castro-Barquero S, Estruch R, Sacanella E. Nutrition and cardiovascular health. Int J Mol Sci. 2018; 19(12): 3988. doi: $10.3390 /$ ijms 19123988 
4. Andersson A, Bryngelsson S. Towards a healthy diet: from nutrition recommendation to dietary advice. Scand J Food Nutr. 2007; 51(1): 31-40. doi: 10.1080/17482970701284338

5. Banwatt ME, La LA, Daboer J, Audu S, Lassa S. Knowledge and intake of fruit and vegetables consumption among adults in an urban community in north central Nigeria. Niger Health J. 2012; 12(1): 1597.

6. Fadupin GT, Ogunkunle MO, Gabriel OO. Knowledge, attitude and consumption pattern of alcoholic and sugar sweetened beverages among undergraduates in a Nigerian institution. Afr J Biomed Res. 2014; 17(2): 1119.

7. Olatona FA, Onabanjo OO, Ugbaja RN, Nnoaham KE, Adelekan DA. Dietary habits and metabolic risk factors for non-communicable diseases in a university undergraduate population. $J$ Health Popul Nutr. 2018; 37: 21. doi: 10.1186/s41043-018-0152-2

8. Oyebode O, Oti S, Chen Y, Lilford RJ. Salt intakes in sub-Saharan Africa: A systematic review and meta-regression. Popul Health Metr. 2016; 14: 1. doi: 10.1186/s12963-015-0068-7

9. Maryniuk MD. From pyramids to plates to patterns: Perspectives on meal planning. Diabetes Spectr. 2017; 30(2): 67-70. doi: $10.2337 /$ ds16-0080

10. Evert AB, Boucher JL, Cypress M, Dunbar SA, Franz MJ, Mayer-Davis EJ, et al. Nutrition therapy recommendations for the management of adults with diabetes. Diabetes Care. 2013; 36(11): 3821-3842. doi: 10.2337/dc13-2042

11. Asogwa IS, Okoye JI, Oni K. Promotion of indigenous food preservation and processing knowledge and the challenge of food security in Africa. J Food Secur. 2017; 5(3): 75-87. doi: 10.12691/ jfs-5-3-3

12. Forwood SE, Ahem A, Holland GJ, Fletcher PC, Marteau TM. Underestimating calorie content when healthy foods are present: An averaging effect or a reference-dependent anchoring effect? PLoS One. 2013; 8(8): e71475. doi: 10.1371/journal.pone.0071475

13. Ukegbu PO. Consumers' knowledge, attitude, and use of food labels in an urban city in southeast Nigeria. Adv Nutr. 2016; 7(1): 22A. doi: $10.1093 /$ advances/7.1.22A

14. American Dietetic Association. Identifying patients at risk: ADA's definitions for nutrition screening and nutrition assessment. Council on Practice (COP) Quality Management Committee. J Am Diet Assoc. 1994; 1994: 838-839. doi: 10.1016/00028223(94)92357-4

15. Sheils JF, Rubin R, Stapleton DC. The estimated costs and savings of medical nutrition therapy: The medicare population. J Am Diet Assoc. 1999; 99: 428-435. doi: 10.1016/S00028223(99)00105-4

16. American Diabetes Association Task Force for Writing Nu- trition Principles and Recommendations for the Management of Diabetes and Related Complications. American Diabetes Association position statement: Evidence-based nutrition principles and recommendations for the treatment and prevention of diabetes and related complications. Diabetes Care. 2002; 102(1): 109-118. doi: 10.1016/s0002-8223(02)90031-3

17. Moller G, Andersen HK, Snorgaard O. A systematic review and meta-analysis of nutrition therapy compared with dietary advice in patients with type 2 diabetes. Am J Clin Nutr. 2017; 106(6): 1394-1400. doi: 10.3945/ajcn.116.139626

18. Davies MJ, D’Alessio DA, Fradkin J, Kernan WN, Mathieu C, Mingrone G. et al. Management of hyperglycemia in type 2 diabetes, 2018. A consensus report by the American Diabetes Association (ADA) and the European Association for the Study of Diabetes (EASD). Diabetes Care. 2018; 41(12): 2669-2701. doi: $10.2337 /$ dci18-0033

19. Schwingshackl L, Chaimani A, Hoffmann G, Schwedhelm C, Boeing H. A network meta-analysis on the comparative efficacy of different dietary approaches on glycaemic control in patients with type 2 diabetes mellitus. Eur J Epidemiol. 2018; 33(2):157-170. doi: 10.1007/s10654-017-0352-x

20. Lacatusu M, Grigorescu E, Floria M, Onofriescu A, Mihai B. The mediterranean diet: From an environment-driven food culture to an emerging medical prescription. Int J Envrons Res Public Health. 2019; 16(6): 942. doi: 10.3390/ijerph16060942

21. Alexandratos N. The Mediterranean diet in a world context. Public Health Nutr. 2006; 9(1A): 111-117. doi: 10.1079/ phn2005932

22. Davidson GI, Ene-Obong HN, Chinma CE. Variations in nutrients composition of most commonly consumed cassava (manihot esculenta) mixed dishes in South-Eastern Nigeria. J Food Quality. 2017; 2017: 6390592. doi: 10.1155/2017/6390592

23. Tariq SH. Dietary prescription in diabetes mellitus. Clin Geriatr Med. 2002; 18(4): 827-833. doi: 10.1016/s0749-0690(02)00038-1

24. American Diabetes Association. Nutrition recommendations and interventions for diabetes: A position statement of the American Diabetes Association. Diabetes Care. 2008; 38(Suppl 1): S61-S78. doi: 10.2337/dc08-S061

25. Pastors JG, Warshaw H, Daly A, Franz M, Kulkarni K. The evidence for the effectiveness of medical nutrition therapy in diabetes management. Diabetes Care. 2002; 25: 608-613. doi: 10.2337/ diacare.25.3.608

26. Sarac L, Butnariu M. Food pyramid- the principles of a balanced diet. Int J NutrPharmac Neurol Dis. 2020; 5(2): 24. doi: 10.14302/issn.2379-7835.ijn-20-3199

27. Georgr B. How to live healthier, longer. Web site guardian. https://guardian.ng/features/science/how-to-live-healthier- 
longer/. Published May 14, 2015. Accessed August 6, 2020.

28. Kulkarni KD. Carbohydrate counting: A practical meal-planning option for people with diabetes. Clinical Diabetes. 2005; 23(3): 120-122. doi: 10.2337/diaclin.23.3.120

29. Ojeleye OA, Damisa MA, Saleh MG, Bonire FS. Determinants of daily per capita calorie intake among rural farming households in Nigeria. J Agric. 2014; 1(2): 5.

30. Ayida M. Are you drinking too much. Web site guardian. https://guardian.ng/features/are-you-drinking-too-much/. Accessed August 6, 2020.
31. Oja F. Calories in Nigerian foods (over 100 foods in one place). Web site fitnigerian. https://www.fitnigerian.com/calories-in-nigerian-foods/. Accessed August 6, 2020.

32. Oluwasogo A. Calories in some popular Nigerian foods. Web site allnigeriainfo. https: / / allnigeriainfo.ng/calories-in-some-popular-nigerian-foods/. Accessed August 6, 2020.

33. Edoho R. Tracking calories in Nigerian foods using myfitnesspal. Web site 9jafoodie. https://9jafoodie.com/tracking-calories-nigerian/. Accessed August 6, 2020. 